\title{
The dynamic experimental study of the application of Selective cationic plugging agents to the binary system flooding and polymer channeling well in Block J16
}

\author{
Yujun Gao', a \\ ${ }^{1}$ Liaohe Oilfield Company Exploration\&Oil Extraction Factory, Liaoning Panjin 124010, China \\ a958004918@qq.com
}

\begin{abstract}
Keywords: Polymer Gather; Cationic; Profile Control and Water Shutoff; Polymer Concentration Abstract. The binary system flooding test site in block J16 has serious polymer gather phenomenon, To solve this problem, applying the way of injecting cationic profile control and water shutoff agent from producing well which provide a polymer gather layer plugging so as to reduce polymer concentration in producing well. The results of physical simulation experiments in laboratory showed that all the selected profile control and water shutoff agent can react with the polymer, which can effectively decrease polymer concentration, delay the time when the polymer appeared and when the peak of the polymer concentration came; This measure can also improve the initial injecting pressure of polymer without reaction product washed out from the core; To the same profile control and water shutoff agent, the larger concentration and injection rate made the injecting pressure get larger, the time when the polymer appeared get longer and the concentration of the polymer in production well became lower; The concentration of profile control and water shutoff agent should be higher than $0.6 \%$, the injected slug should be more than $0.5 \mathrm{PV}$.
\end{abstract}

\section{Introduction}

With binary system flooding the number of polymer gather wells in block J16 of Liaohe oilfield was gradually increasing and the concentration of polymer in production well got higher, the number of production wells that polymer concentration was higher than $200 \mathrm{mg} / \mathrm{L}$ was thirteen, six of which were the polymer gather wells , their water cut was higher than $90 \%$, so the development efficiency of binary system flooding was seriously influenced. Because of polymer gather, displacement of polymer became inefficient circulation and it leaded to waste; it also made high water production and low oil production, leaded to sand production in oil wells which influences normal production. The existing technologies of plugging polymer were short of interaction with the polymer underground, so they couldn't fix the underground polymer effectively and inject difficultly, and had small radius of plugging, they couldn't meet the demand of preventing from polymer gather.

How to prevent from polymer gather, achieve better results in polymer flooding? This requires that we take full advantage of the remaining polymer of big channel in polymer gather wells layer of binary system flooding, develop new selective profile control and water shutoff agent to block off polymer gather pore channel, develop new technologies which can not only prevent from polymer gather but also reduce formation heterogeneity, extend the polymer sweep efficiency, so as to play a due role for the polymer.

\section{Experimental Conditions}

Experimental Apparatus. Apparatus: constant-flux pump, pressure sensor, standard digital pressure gauge, vacuum pump, thermostat, electronic scales, magnetic stirrers, Model 721 Spectrophotometer; Other accessories: intermediate container, valves, nylon pipelines, bull plugs, tee-junctions, cross pipes etc.

Experimental Chemical Agents. The chemical agents for experiment are polymer with molecular weight $2500 \times 10^{4}$ provided by site and selected cation profile control and water shutoff agent B. 
Experiment Used Water. The simulative water used in the experiment is prepared by distilled water on the basis of actual reservoir water salinity in test site, it's salinity is $2467.2 \mathrm{mg} / \mathrm{L}$.

Experimental Temperature. The experimental temperature is $55^{\circ} \mathrm{C}$.

Experimental Cores.The experimental three layers of heterogeneous artificial cores are made by the parameters of reservoir physical property in tentative zone, the geometric dimensioning of cores is $4.5 \mathrm{~cm} \times 4.5 \mathrm{~cm} \times 30 \mathrm{~cm}$, mean permeability is $1600 \times 10^{-3} \mu \mathrm{m}^{2}$.

Experimental Programs. Use three different concentrations of $0.3 \%, 0.6 \%, 0.8 \%$ profile control and water shutoff agents for core flooding experiment, evaluate the result; Use six different plug sizes of $0,0.3,0.4,0.5,0.6,1 \mathrm{PV}$ profile control and water shutoff agents for core flooding experiment, evaluate the result; Under same quantity of profile control and water shutoff agent, change system concentration and slug size for core flooding experiment, evaluate the result.

\section{Experimental Results and Analysis}

The Effect of Concentration of Profile Control and Water Shutoff Agent on Profile Control and Water Shutoff Result. The profile control and water shutoff systems for the experiment were prepared by profile control and water shutoff agent B which concentration were $0.3 \%, 0.6 \%, 0.8 \%$, at first, injected $0.5 \mathrm{PV}$ of profile control and water shutoff system backward from the output port end of three cores, secondly, injected the polymer solution forward which molecular weight was $2500 \times 10^{4}$, concentration was $0.2 \%$, their injected volumes were all $0.6 \mathrm{PV}$, their injection rate was $0.6 \mathrm{~mL} / \mathrm{min}$, at last apply water drive, the experimental results are shown in Fig. $1 \sim 2$.

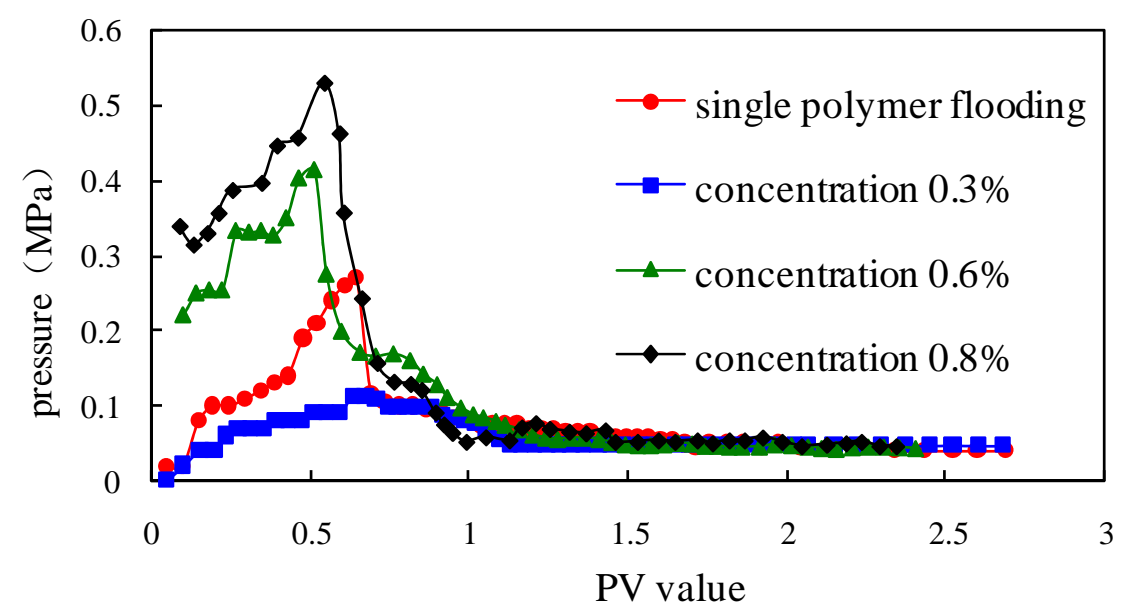

Fig. 1 The relation curve between pressure differential and injection pore volume multiple

Fig. 1 is the relation curve between pressure differential and injection pore volume multiple, the pressure in every curves is improving as injection pore volume multiple increases, after the pressure get the maximum, it descends gradually and finally becomes stable. The curve of profile control and water shutoff system which concentration is $0.3 \%$ changes slightly; with the concentration of profile control and water shutoff agent increasing the initial pressure is increasing and the maximum pressure is increasing gradually, but the last stable pressure of each profile control and water shutoff system has little difference.

This is because in the initial stage of polymer injection, polymer didn't sufficiently react with low concentration profile control and water shutoff agent, this reaction produce little flocculent precipitation, it can't form large area of plugging, the polymer can still slowly advance from big pore channel; but the high concentration profile control and water shutoff agent can sufficiently react with 
polymer quickly in the initial time and produce a large number of precipitation, the precipitation can effectively block big pores so as to compel polymer stream to flow into relatively smaller pores; when the concentration of profile control and water shutoff agent is higher, after lots of polymer participates in coagulation reaction, the concentration and viscosity of the rest polymer are all lower.

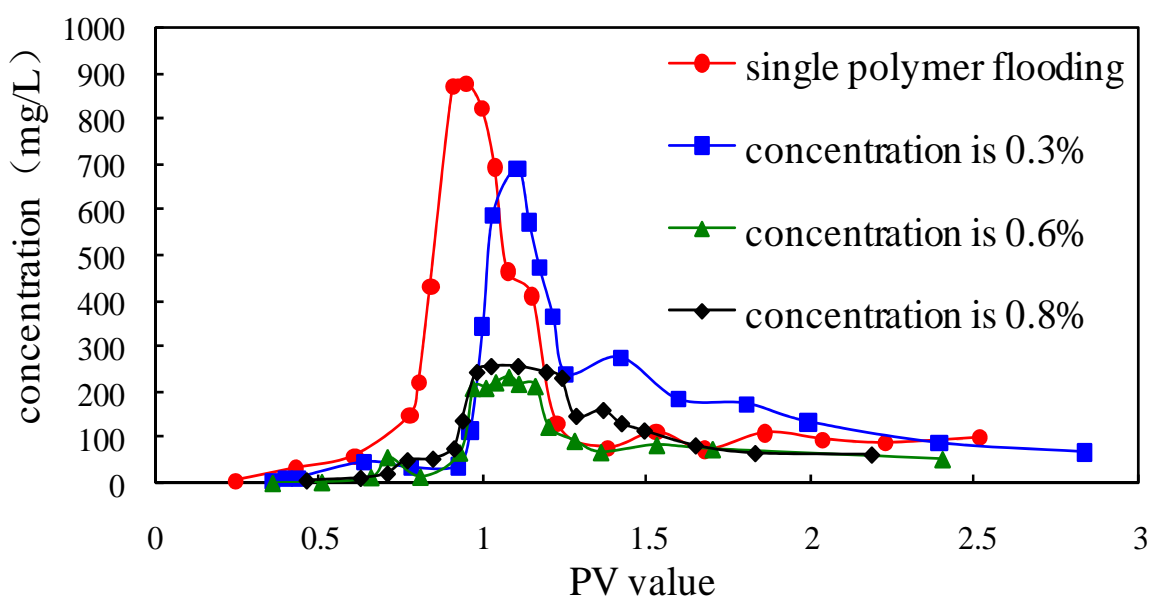

Fig. 2 The relation curve between produced fluid concentration and injection pore volume multiple

Fig. 2 is the relation curve between produced fluid concentration and injection pore volume multiple, the polymer concentration of produced fluid is gradually improving as injected PV increases, after the concentration gets the maximum, it descends gradually and finally becomes stable. The produced polymer concentrations of different concentrations of profile control and water shutoff agent are all lower than that of polymer flooding, this shows that the profile control and water shutoff agent can effectively react with injection polymer in the core. The lowest peak concentration of produced fluid occurs in the concentration of $0.6 \%$, and the peak lasts a longer time, it is not far from the profile control and water shutoff agent system whose concentration is $0.8 \%$; the concentration of production of the profile control and water shutoff system whose concentration is $0.3 \%$ is higher than the other two systems, and the peak concentration is also the highest of all.

The Influence of Profile Control and Water Shutoff Agent Slug Size to the Effect. The profile control and water shutoff system for the experiment was prepared by profile control and water shutoff agent $\mathrm{B}$ whose concentration was $0.6 \%$, at first, injected $0.3 \mathrm{PV}, 0.4 \mathrm{PV}, 0.5 \mathrm{PV}$ and $0.6 \mathrm{PV}$ of profile control and water shutoff systems backward from the output port end of four cores, secondly, injected the polymer solution forward whose molecular weight was $2500 \times 10^{4}$, and concentration was $0.2 \%$, their injected volumes were all $0.6 \mathrm{PV}$, their injection rate was $0.6 \mathrm{~mL} / \mathrm{min}$, at last apply water drive, the experimental results are shown in Fig. $3 \sim 4$.

Fig. 3 is the relation curve between pressure differential and injection pore volume multiple under the different injection volume conditions, the pressure in every curves is improving as injection pore volume multiple increases, after the pressure get the maximum, it descends gradually and finally becomes stable, and the highest pressures are all higher than that of usual polymer flooding.

The curve of the profile control and water shutoff system whose injection volume is $0.3 \mathrm{PV}$ changes most steeply; with the injection volume of profile control and water shutoff agent B increasing, the initial pressure is improving. The pressure changes become fluctuating gradually in rising phase, the highest pressures differential produced by the three systems of different injection volumes have little difference, but the time of reaching the highest pressure is earlier and earlier with more agents injected. after the pressure become stable, the pressures of each injection volume have little difference.

After inject the profile control and water shutoff agent, the polymer need to break through the resistance caused by coagulation reaction and front slug in the process of moving forward, when the polymer react with the same concentration of profile control and water shutoff agent, it will produce 
the same precipitation volumes, then the resistance is correspondingly same. So when the injection volume and the slug size improve, the resistance correspondingly increases, then pressure differential becomes large.

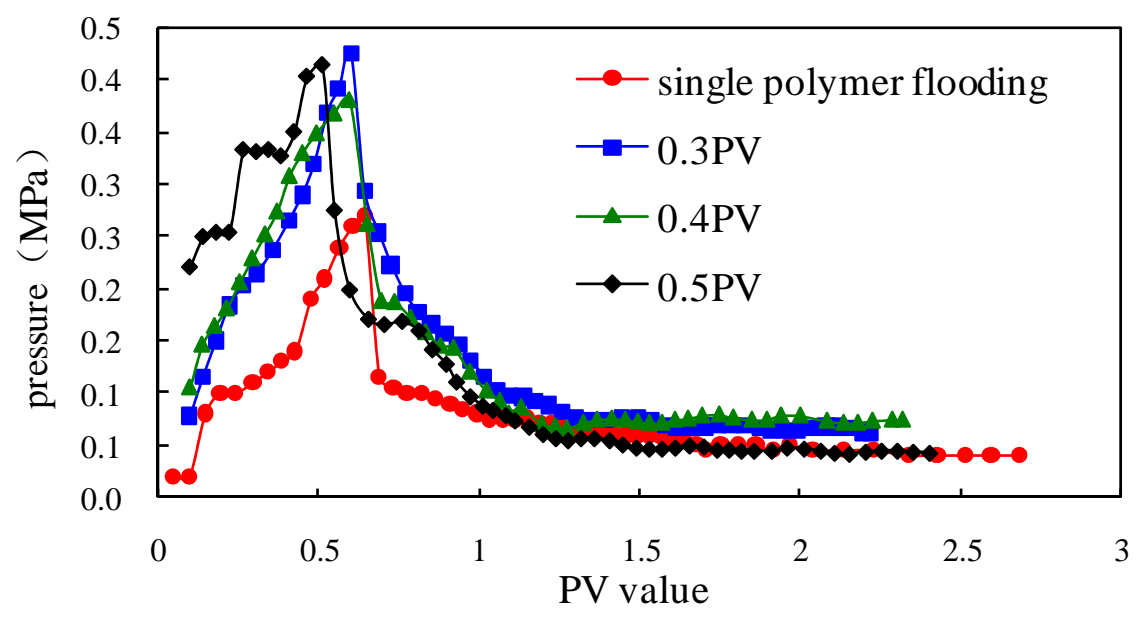

Fig. 3 The relation curve between pressure differential and injection pore volume multiple

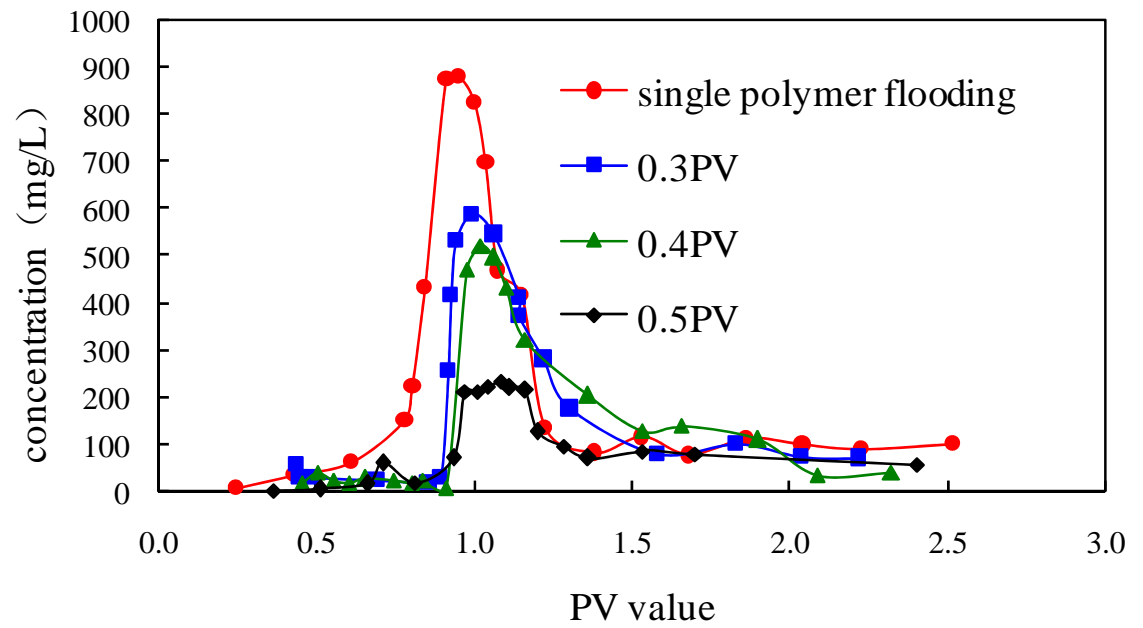

Fig. 4 The relation curve between produced polymer concentration and injection pore volume multiple

Fig. 4 is the relation curve between produced polymer concentration and injection pore volume multiple under the condition of different sizes of slug, when the injection quantity is $0.3 \mathrm{PV}$, the peak concentration of polymer is highest and the first time to see polymer from producing well is the earliest, meanwhile, with the injecting rate increasing, the peak concentration of polymer come out later and the output of polymer concentration is smaller.

The first time to see polymer is when the injection volume of plugging agent $\mathrm{B}$ is $0.43 \mathrm{PV}$ under the concentration condition that corresponding injection rate is $0.3 \mathrm{PV}$, and the peak concentration is $588 \mathrm{mg} / \mathrm{L}$, it is not substantially delayed the first time to see polymer from the producing well and reduce the output concentration, but the other kinds of injections all can delay the first time to see polymer from producing well and reduce the peak concentration in different degrees, when injection volume is $0.5 \mathrm{PV}$, the peak concentration reach the minimum and it is only $234 \mathrm{mg} / \mathrm{L}$. When injection 
volume increases, the pressure differential is also improved, when the injection volume is $0.6 \mathrm{PV}$, the pressure differential reached 2.0 MPa and did not see the liquid, so we can see a large number of the plugging agent injection can produce strong block.

Impact of Different Injection Patterns on Plugging Effect. This experiment chose plugging agent $\mathrm{B}$, under the condition of same plugging agent dosage, we changed the concentrations and slug sizes of profile control system and did core displacement experiments. First, we injected plugging agent $\mathrm{B}$ from outlet of the core backward according to the ways of injection in table 1 , then we injected polymer solution which molecular weight is $2500 \times 10^{4}$ and concentration is $0.2 \%$, the injection pore volumes were all $0.6 \mathrm{PV}$ and injection rates were all $0.6 \mathrm{~mL} / \mathrm{min}$, at last applied water flooding, and the final results are shown in fig. $5 \sim 6$.

Table 1 the injection ways of plugging agent

\begin{tabular}{c|c|c}
\hline project numbers & $\begin{array}{c}\text { The plugging agent concentrations } \\
(\%)\end{array}$ & The plugging agent slug sizes (PV) \\
\hline Injection way of no.1 & 0.8 & 0.3 \\
\hline Injection way of no.2 & 0.6 & 0.5 \\
\hline Injection way of no.3 & 0.3 & 1 \\
\hline
\end{tabular}

Result shows that when the plugging agent's dosage is equal, the three ways all can postpone the first time to see polymer from producing well and reduce the concentration of polymer, at the same time, they can delay the coming time of the polymer peak, but the peak concentration and maximum pressure differential have big differences. The third injection way's first time to see polymer from producing well is the latest, and the polymer peak concentration is $665 \mathrm{mg} / \mathrm{L}$ which is higher relatively, and the minimum of maximum pressure differential is $0.186 \mathrm{MPa}$; The first injection way's first time to see polymer from producing well is the earliest, the polymer peak concentration is a little lower, it is $545 \mathrm{mg} / \mathrm{L}$, but the appearing time of the polymer peak concentration is earlier and it is $0.88 \mathrm{PV}$, it also make the biggest pressure differential that reached $0.501 \mathrm{MPa}$; The second injection way's peak concentration of polymer is the lowest. Take all factors in consideration, such as improving the pressure differential, delaying the first time to see polymer and reducing the peak concentration of polymer, we suggest that the plugging agent concentration should be higher than $0.6 \%$, and the injected slug volume should be higher than $0.5 \mathrm{PV}$.

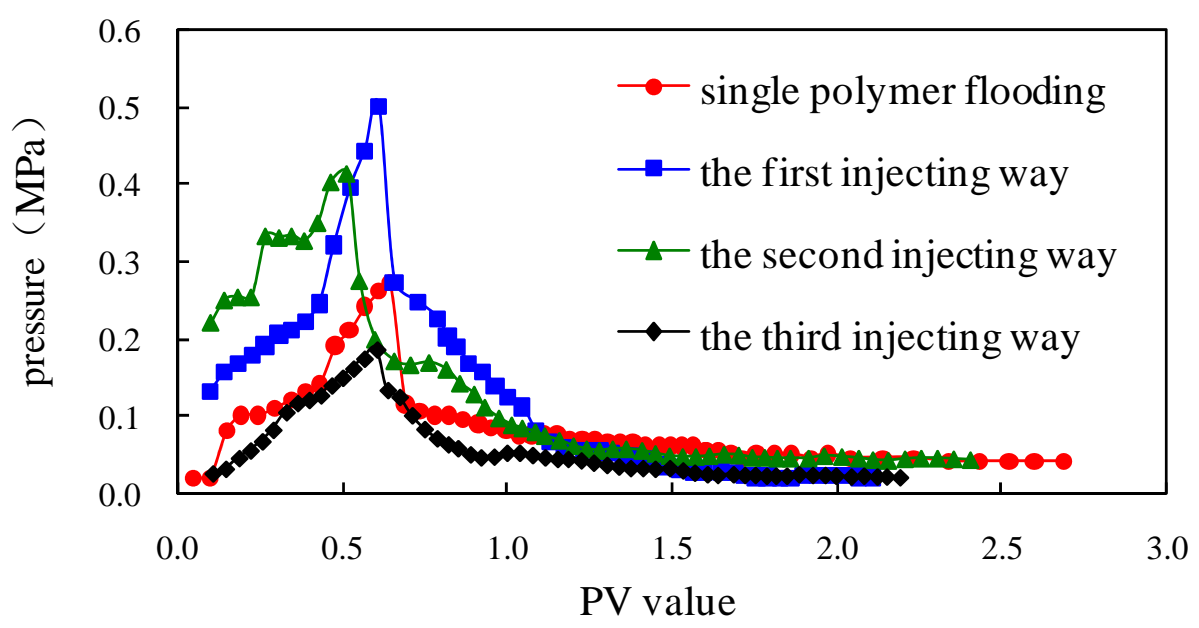

Fig. 5 The relation curve between pressure differential and injection pore volume multiple 


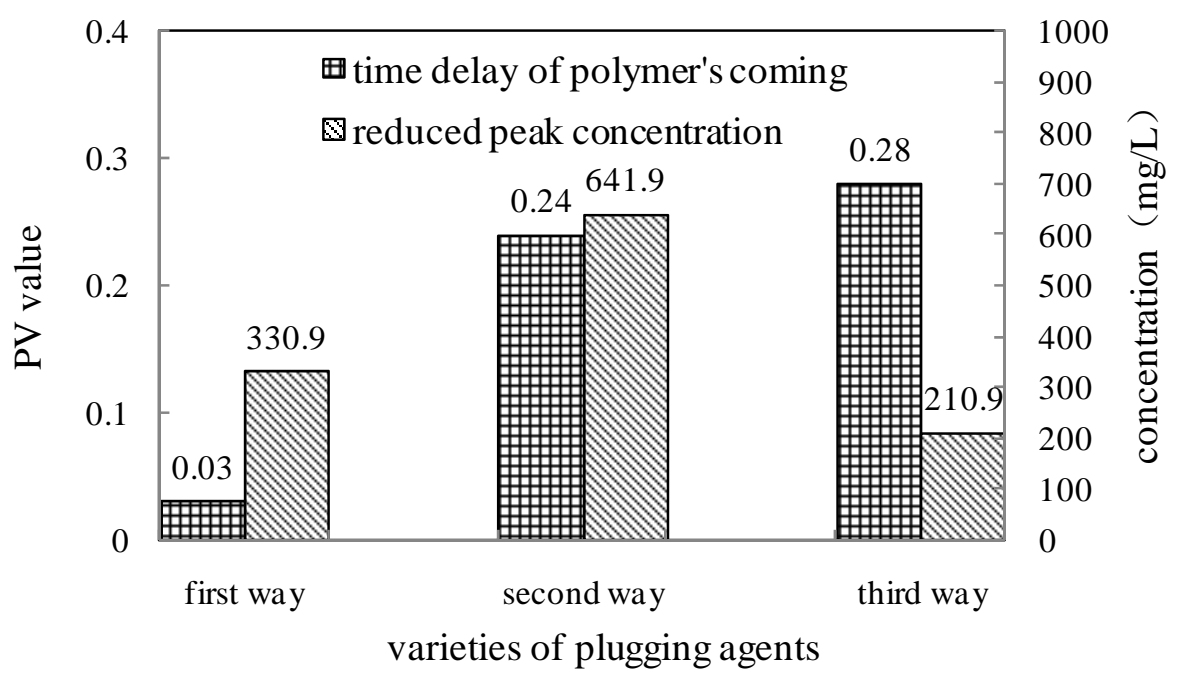

Fig. 6 The histogram of profile control and water shutoff effect for different injecting ways

\section{Conclusions}

For the same plugging agent, when the concentration, injection and injection pressure differential improved, the first time to see the polymer from the producing well became later and the peak concentration became lower, but as the quantity of polymer is definite ,after the concentration and injection volume increased to a certain extent, the reduction of the peak concentration changed little;

In the same dosage condition of the plugging agent, the injection way of high concentration and small slug made the pressure differential big, but the polymer came early from the producing well; the injection way of low concentration and big slug make the pressure differential small, and the polymer come late from the producing well, but the peak concentration of polymer was highest;

The concentration of plugging agent should be higher than $0.6 \%$, the volume of injected slug should be higher than $0.5 \mathrm{PV}$.

\section{References}

[1] Xiaowei Zhang, Xihui Lv, Shan Xu etc. Oil drilling technology, 2002, 5 (24): 56-58.(In Chinese)

[2] Xiaohua Zhang. Zhejiang: Zhejiang University, 2011. (In Chinese)

[3] Wei Wang. Daqing: Northeast Petroleum University, 2007. (In Chinese)

[4] Caili Dai, Fulin Zhao, Jianhong Xiao etc. Journal of xi 'an petroleum university (natural science edition), 2006, 6 (21) : 56-60. (In Chinese)

[5] Bailing Kong, Zhaoke Kong, Zhengxin Wang etc. Journal of oil, 2008, 2 (29): 262-265. (In Chinese) 